\title{
Deep Sequencing Reveals Potential Antigenic Variants at Low Frequencies in Influenza A Virus-Infected Humans
}

\author{
Jorge M. Dinis, ${ }^{a}$ Nicholas W. Florek, ${ }^{a}$ Omolayo O. Fatola, ${ }^{b}$ Louise H. Moncla, ${ }^{a}$ James P. Mutschler, ${ }^{\text {a,d }}$ Olivia K. Charlier, ${ }^{\text {a }}$ \\ Jennifer K. Meece, ${ }^{c}$ Edward A. Belongia, ${ }^{c}$ Thomas C. Friedrich ${ }^{\mathrm{a}, \mathrm{d}}$ \\ Department of Pathobiological Sciences, University of Wisconsin School of Veterinary Medicine, Madison, Wisconsin, USAa; Department of Biological Sciences, University \\ of Maryland, Baltimore, Maryland, USA ${ }^{\mathrm{b}}$; Center for Clinical Epidemiology and Population Health, Marshfield Clinic Research Foundation, Marshfield, Wisconsin, USAc; \\ Wisconsin National Primate Research Center, Madison, Wisconsin, USA
}

\section{ABSTRACT}

Influenza vaccines must be frequently reformulated to account for antigenic changes in the viral envelope protein, hemagglutinin (HA). The rapid evolution of influenza virus under immune pressure is likely enhanced by the virus's genetic diversity within a host, although antigenic change has rarely been investigated on the level of individual infected humans. We used deep sequencing to characterize the between- and within-host genetic diversity of influenza viruses in a cohort of patients that included individuals who were vaccinated and then infected in the same season. We characterized influenza HA segments from the predominant circulating influenza A subtypes during the 2012-2013 (H3N2) and 2013-2014 (pandemic H1N1; H1N1pdm) flu seasons. We found that HA consensus sequences were similar in nonvaccinated and vaccinated subjects. In both groups, purifying selection was the dominant force shaping HA genetic diversity. Interestingly, viruses from multiple individuals harbored low-frequency mutations encoding amino acid substitutions in HA antigenic sites at or near the receptor-binding domain. These mutations included two substitutions in H1N1pdm viruses, G158K and N159K, which were recently found to confer escape from virusspecific antibodies. These findings raise the possibility that influenza antigenic diversity can be generated within individual human hosts but may not become fixed in the viral population even when they would be expected to have a strong fitness advantage. Understanding constraints on influenza antigenic evolution within individual hosts may elucidate potential future pathways of antigenic evolution at the population level.

\section{IMPORTANCE}

Influenza vaccines must be frequently reformulated due to the virus's rapid evolution rate. We know that influenza viruses exist within each infected host as a "swarm" of genetically distinct viruses, but the role of this within-host diversity in the antigenic evolution of influenza has been unclear. We characterized here the genetic and potential antigenic diversity of influenza viruses infecting humans, some of whom became infected despite recent vaccination. Influenza virus between- and within-host genetic diversity was not significantly different in nonvaccinated and vaccinated humans, suggesting that vaccine-induced immunity does not exert strong selective pressure on viruses replicating in individual people. We found low-frequency mutations, below the detection threshold of traditional surveillance methods, in nonvaccinated and vaccinated humans that were recently associated with antibody escape. Interestingly, these potential antigenic variants did not reach fixation in infected people, suggesting that other evolutionary factors may be hindering their emergence in individual humans.

Slion easo easonal influenza A epidemics cause an estimated 3 to 5 million cases of severe respiratory illness each year, resulting in approximately 250,000 to 500,000 deaths worldwide (1). Available influenza vaccines only provide moderate protection against infection and illness. Vaccine effectiveness can vary greatly by season, but the average effectiveness at preventing illness has been estimated to be $59 \%$ (2). Even when there is good antigenic match between circulating viruses and vaccine strains, people can become infected despite being vaccinated earlier in the same season, a situation known as vaccine failure (3-5).

Viral antigenicity is influenced by multiple factors, including the accumulation of point mutations in the gene encoding the viral attachment protein hemagglutinin (HA), the specificity and avidity of $\mathrm{HA}$ for its receptor, and epistatic interactions within HA and between gene segments $(6,7)$. The HA protein has five classically defined antigenic sites that are important for the recognition of neutralizing antibodies; amino acid substitutions in these sites can significantly change viral antigenicity $(8,9)$. For example, "antigenic cartography" studies demonstrated that H3N2 strains cir- culating from 1968 to 2003 formed 11 distinct "antigenic clusters" (10). Transitions between antigenic clusters occur as variant viruses emerge unpredictably in the population and replace older viruses in circulation (11). Recently, Koel et al. found that single amino acid substitutions in one of seven residues near the HA receptor-binding domain were responsible for the majority of previously observed $\mathrm{H} 3 \mathrm{~N} 2$ antigenic cluster transitions; these

Received 30 December 2015 Accepted 3 January 2016

Accepted manuscript posted online 6 January 2016

Citation Dinis JM, Florek NW, Fatola OO, Moncla LH, Mutschler JP, Charlier OK,

Meece JK, Belongia EA, Friedrich TC. 2016. Deep sequencing reveals potential

antigenic variants at low frequencies in influenza A virus-infected humans. J Virol

90:3355-3365. doi:10.1128/JVI.03248-15.

Editor: S. Schultz-Cherry

Address correspondence to Thomas C. Friedrich, thomasf@primate.wisc.edu.

J.M.D. and N.W.F. contributed equally to this article.

Copyright @ 2016, American Society for Microbiology. All Rights Reserved. 
seven residues have been said to form an "antigenic ridge" on HA (12). Similarly, eight residues were identified in H1N1pdm HA that could lead to escape from neutralizing antibodies (13).

While the molecular basis of antigenic change in influenza is becoming increasingly well understood, the evolutionary processes by which antigenic variants emerge are less clear, particularly on the scale of the individual host. In a host, influenza viruses exist as a diverse collection of genetically similar variants that arise due to low-fidelity genome replication, rapid replication kinetics, and high viral loads $(14,15)$. The level of within-host genetic diversity is determined through random mutation, and the action of natural selection, which can either promote genetic diversification or purify deleterious mutations from the virus population. High within-host diversity is thought to enable influenza viruses to rapidly adapt to changing environments $(16,17)$. However, until recently it was difficult to study the degree to which viral genetic diversity encodes antigenic diversity and contributes to the emergence of antigenic variants within individual hosts. Traditional surveillance methods based on Sanger sequencing cannot resolve variants present below $20 \%$ of the viral population (18). In contrast, deep sequencing can detect variants present at much lower frequency, revealing for example how low-frequency drug-resistant variants can rapidly emerge and become dominant after oseltamivir treatment in immunocompromised individuals (19). Moreover, we recently showed that HA variants present below the detection limit of Sanger sequencing could be transmitted via respiratory droplets (20), suggesting viral variants present at low frequency in individual hosts may have a previously unappreciated role in influenza virus biology.

We used deep sequencing to determine how viral variants potentially encoding antigenic change are generated and selected during human infection, using respiratory samples collected from patients presenting to clinics with acute influenza infections during two recent influenza seasons. Our patient population included subjects with vaccine failure, affording us the opportunity to determine whether within-host viral populations differed between vaccinated and nonvaccinated subjects. We sequenced viruses directly from clinical samples without isolation in eggs or passage in tissue culture. Viral populations did not differ at the consensus level between vaccinated and nonvaccinated subjects. Withinhost HA segment genetic diversity varied considerably among humans, although most viral polymorphisms were typically present either at or near fixation (90 to $100 \%$ of viral sequences) or at low frequency ( 1 to $10 \%$ ) relative to the relevant vaccine strain sequence. Patterns of HA segment diversity were consistent with viruses undergoing purifying selection to maintain fit viral populations. Interestingly, we detected nonsynonymous mutations that had previously been shown to confer escape from neutralizing antibodies in both $\mathrm{H} 3 \mathrm{~N} 2$ and $\mathrm{H} 1 \mathrm{~N} 1 \mathrm{pdm}$ viruses infecting both nonvaccinated and vaccinated subjects. These mutations were always detected at low frequencies in the viral population. Together, our data suggest that putative influenza antigenic escape variants are generated in influenza virus-infected humans but often do not become fixed in the virus population.

\section{MATERIALS AND METHODS}

Study population. The source population for this study included residents of the Marshfield Epidemiologic Study Area (MESA), a populationbased cohort of approximately 54,000 people in a 14-zip-code area surrounding the Marshfield Clinic campus in Marshfield, Wisconsin (21). In the 2012-13 and 2013-14 seasons, most community-dwelling MESA residents aged $\geq 6$ months were eligible to be recruited for a separate study of influenza vaccine effectiveness during an outpatient encounter for acute respiratory illness with cough. Patients meeting symptom criteria were eligible if the duration of illness was $\leq 7$ days. Participants completed an interview to assess illness onset and symptoms. Individuals were considered vaccinated if they had received an influenza vaccine for the current influenza season $\geq 14$ days prior to illness onset. We obtained nasal and oropharyngeal swabs from nonvaccinated and vaccinated participants aged $\geq 9$ years; swabs were combined in viral transport media for testing. Influenza infection was confirmed using quantitative reverse transcription-PCR (qRT-PCR) (22). During the 2012-13 and 2013-14 seasons, subtypes H3N2 and 2009 pandemic H1N1 (H1N1pdm), respectively, were dominant in the United States $(4,23)$; for this reason, we only had access to H3N2 during the 2012-13 season and H1N1pdm viruses during the 2013-14 season.

The Marshfield Clinic Institutional Review Board approved study procedures. Informed consent was obtained from all adults and parents/ guardians of children. Additional details on the vaccine effectiveness studies for which these human samples were originally collected have been published $(4,23)$.

Template preparation. Total nucleic acids were extracted from clinical specimens using the RNeasy minikit (Qiagen, USA). Influenza vRNAs were reverse transcribed using the Uni12-F (AGCAAAAGCAGG) primer (24) with Superscript III reverse transcriptase (Invitrogen, USA) according to the manufacturer's instructions. Single-stranded cDNA was used as a template for PCR amplification to amplify the HA genes using either the primers H3N2-F (AGCAAAAGCAGGGGATAATTC) and H3N2-R (AG TAGAAACAAGGGTGTTTTTA) or the primers H1N1pdm-F (ATATAC GCGTAGCGAAAGCAGGGGAA) and H1N1pdm-R (ATATACGCGTA GTAGAAACAAGGTGT) with high-fidelity Phusion $2 \times$ master mix (New England BioLabs, Inc., USA). PCR was performed by incubating the reaction mixtures at $98^{\circ} \mathrm{C}$ for $20 \mathrm{~s}$, followed by 35 cycles of $98^{\circ} \mathrm{C}$ for $10 \mathrm{~s}$, $57^{\circ} \mathrm{C}$ for $10 \mathrm{~s}$, and $72^{\circ} \mathrm{C}$ for $1 \mathrm{~min}$, followed by a final extension step at $72^{\circ} \mathrm{C}$ for $10 \mathrm{~min}$. PCR products were separated by electrophoresis on a $1 \%$ agarose gel. The band corresponding to the full-length HA gene segment was excised, and the DNA was recovered using a QIAquick gel extraction kit (Qiagen).

Deep sequencing. Gel-purified PCR products were quantified using the Qubit dsDNA high-sensitivity kit (Invitrogen). Purified PCR products were made compatible for deep sequencing using the Nextera XT DNA sample preparation kit (Illumina, USA). Each sample was enzymatically fragmented and tagged with short oligonucleotide adapters, followed by 14 cycles of PCR for template barcoding. Barcoded H3N2 and H1N1pdm libraries were pooled to a final concentration of $2 \mathrm{nM}$, and $10 \mu \mathrm{l}$ of the 2 $\mathrm{nM}$ pooled library was denatured in $10 \mu \mathrm{l}$ of $0.2 \mathrm{~N} \mathrm{NaOH}$ for $5 \mathrm{~min}$. Denatured pooled libraries were diluted to a final concentration of $12 \mathrm{pM}$ with a PhiX-derived control library accounting for $1 \%$ of total DNA. Next, $600 \mu \mathrm{l}$ of diluted-denatured template was added to a 500 -cycle reagent cartridge. Illumina MiSeq run settings were entered into the sample sheet by using Illumina Experiment Manager Software v1.3.66 (workflow [FASTQ]; assay [Nextera XT]; chemistry [Amplicon]; reads, $250 \times 250)$. Sequence reads were imported into CLC Genomics Workbench, version 7.5.2 (CLC bio, Denmark). Sequence reads were trimmed using a quality score cutoff of Q30 (i.e., 1 error per 1,000 sequenced bases). For each sample, we mapped trimmed sequence reads against a vaccine strain HA reference sequence: A/Victoria/361/2011 (H3N2; KC306165) or A/California/07/2009 (H1N1pdm; CY121680).

Between-host evolutionary analysis. For each reference-based mapping, we extracted a consensus sequence that consists of the majority nucleotide at each nucleotide site. Consensus sequences were imported into Geneious Version 5.6.3 (Biomatters, Ltd., New Zealand). In Geneious, we created individual alignments using the MUSCLE alignment algorithm (25) for H3N2 and H1N1pdm HA gene sequences. Phylogenetic trees were constructed from alignments in PHYML version 3.0 (26, 
TABLE 1 Descriptive characteristics of influenza A cases by season

\begin{tabular}{llll}
\hline Characteristic & $\begin{array}{l}2012-13 \\
(n=68)\end{array}$ & $\begin{array}{l}2013-14 \\
(n=46)\end{array}$ & $\begin{array}{l}\text { Total } \\
(n=114)\end{array}$ \\
\hline Age group (yrs) & 18 & 9 & 27 \\
$\quad<9$ & 5 & 5 & 10 \\
$9-17$ & 20 & 17 & 37 \\
$8-49$ & 25 & 15 & 40 \\
$\geq 50$ & & & \\
Vaccination status & & & \\
Nonvaccinated & 37 & 32 & 69 \\
Vaccinated & 31 & 14 & 45 \\
IIV & 24 & 10 & 34 \\
LAIV & 3 & 4 & 7 \\
HD & 2 & 0 & 2 \\
Vaccinated, unknown type & 2 & 0 & 2 \\
Interval from onset to swab (days) & & & \\
$\quad<3$ & 34 & 29 & 63 \\
3-4 & 22 & 8 & 30 \\
5-7 & 12 & 9 & 21 \\
Swab collection (mo) & & & \\
December & & & \\
January & & 22 & 35 \\
February & 13 & 22 & 59 \\
March & 37 & 2 & 19 \\
Influenza A virus subtype & 17 & 0 & 1 \\
H3N2 & 1 & & \\
H1N1pdm & & & \\
\hline & 68 & & \\
\hline
\end{tabular}

27) using the HKY 85 substitution model with 1,000 bootstrap replicates to assess statistical confidence. The consensus HA gene segments has been deposited in NCBI GenBank under accession numbers KR611199 to KR611312.

Within-host evolutionary analysis. Single-nucleotide polymorphisms (SNPs) were detected, at nucleotide positions with coverage of at least 100 sequence reads and a central base quality score of $\geq Q 30$, relative to a vaccine strain reference sequence (A/Victoria/361/2011 H3N2 or A/California/07/2009 H1N1pdm) using CLC Genomics Workbench version 7.5.2. SNPs were only considered for subsequent analysis if detected at a cutoff frequency of $\geq 1 \%$, a validated threshold that reduces the carryover of errors introduced by reverse transcription, amplification, or basecalling (20). The nucleotide diversity statistics $\pi_{\mathrm{N}}$ and $\pi_{\mathrm{S}}$ were calculated in PoPoolation version 1.2.2 (28) using subsampled sequence mappings containing 1,000 randomly chosen sequences per nucleotide position to minimize potential coverage bias. HA protein structures were created with MacPymol (http://www.pymol.org/). Mature H3N2 numbering is used throughout the manuscript for H3N2 and H1N1pdm viruses.

\section{RESULTS}

Participant characteristics. Samples used for the present study represent a cross-sectional sampling of combined nasal and oropharyngeal swabs collected as part of a separate study of influenza vaccine effectiveness from 114 human subjects aged $\geq 9$ years with medically attended acute respiratory illness (MAARI) who tested positive for influenza A virus by qRT-PCR (Table 1). Unfortunately, neither time-serial respiratory samples nor sera were available from these subjects. As a result, we were not able to assess antibody titers in these subjects. The mean intervals \pm the standard deviations (SD) from illness onset to sample collection were
$2.7 \pm 1.5$ and $2.7 \pm 1.8$ days, respectively, for subjects who tested positive for $\mathrm{H} 3 \mathrm{~N} 2$ and $\mathrm{H} 1 \mathrm{~N} 1 \mathrm{pdm}$ infection. The samples assessed here were collected from 68 individuals infected with H3N2 during the 2012-13 season and from 46 individuals infected with H1N1pdm during the 2013-14 season. In total, 45 of these subjects were vaccinated in the season in which they were infected, and 69 were nonvaccinated. As shown in Table 1, 34 vaccinated subjects received an inactivated influenza vaccine (IIV), 7 received a live attenuated influenza vaccine (LAIV), and 2 received high-dose IIV (HD); the vaccine type was not recorded for an additional 2 subjects (unknown [UN]).

Deep-sequencing HA segments. Because mutations near the receptor-binding pocket can be introduced during propagation of clinical specimens in eggs (29-31), we sequenced PCR-amplified viral nucleic acids extracted directly from swabs. Amplified HA genes were prepared for deep sequencing using the Illumina MiSeq because of its high throughput and low error rate $(32,33)$. The mean sequence coverages \pm the SD of HA were 16,370.91 \pm $10,887.82(\mathrm{H} 3 \mathrm{~N} 2)$ and 13,786.92 \pm 5,711.98 (H1N1pdm) sequences per nucleotide site.

Vaccine failure is not associated with particular HA sequences. We first sought to determine whether vaccine failure might be associated with selection for HA variants in vaccinated individuals. We constructed maximum-likelihood phylogenetic trees using nearly full-length nucleotide HA consensus sequences (Fig. 1). The phylogenies yielded topologies consistent with established relationships among influenza strains circulating during the 2012-13 and 2013-14 seasons $(34,35)$. All H1N1pdm viruses infecting our subjects belonged to genetic subgroup $6(46 / 46)$. Almost all H3N2 viruses belonged to clade 3C, with the exception of two viruses belonging to clade 6. Currently circulating H3N2 clade $3 \mathrm{C}$ viruses can be further resolved into multiple subgroups with differing degrees of antigenic relatedness (35). Within our subjects, $72.7 \%(48 / 66)$ of clade $3 \mathrm{C} \mathrm{H} 3 \mathrm{~N} 2$ viruses belonged to subgroup 3C.2 and 27.3\% (18/66) belonged to subgroup 3C.3.

We examined our phylogenies for monophyletic clades consisting primarily of HA consensus sequences from vaccinated subjects, which we would expect to observe if in either season, antibodies boosted by vaccination selected for variant viruses detectable at the consensus level in subjects with vaccine failure. Instead of this monophyletic clustering, sequences from vaccinated and nonvaccinated individuals were generally interspersed throughout the trees (Fig. 1). We did detect one monophyletic clade consisting of HA sequences entirely from vaccinated individuals ( $n=2$; H3N2 genetic subgroup 6 ), but no sequences of subgroup 6 viruses from nonvaccinated subjects were available for comparison. Together, these data indicate that vaccine failure was not associated with mutations in the HA gene detectable at the consensus level in either season studied.

Action of natural selection on HA genes in human infections. We considered the possibility that vaccine-induced antibodies could act to eliminate some variants from the infecting viral "swarm" without altering the consensus sequence, which might be expected if they attenuate the infecting dose but fail to block infection. In this case, within-host HA genetic diversity might be reduced in cases of vaccine failure relative to virus populations in nonvaccinated individuals. To estimate within-host HA nucleotide diversity we calculated the statistic $\pi$. $\pi_{N}$, or nonsynonymous diversity, describes the frequency of pairwise sequence differences within a virus population that encode an amino acid change. Sim- 

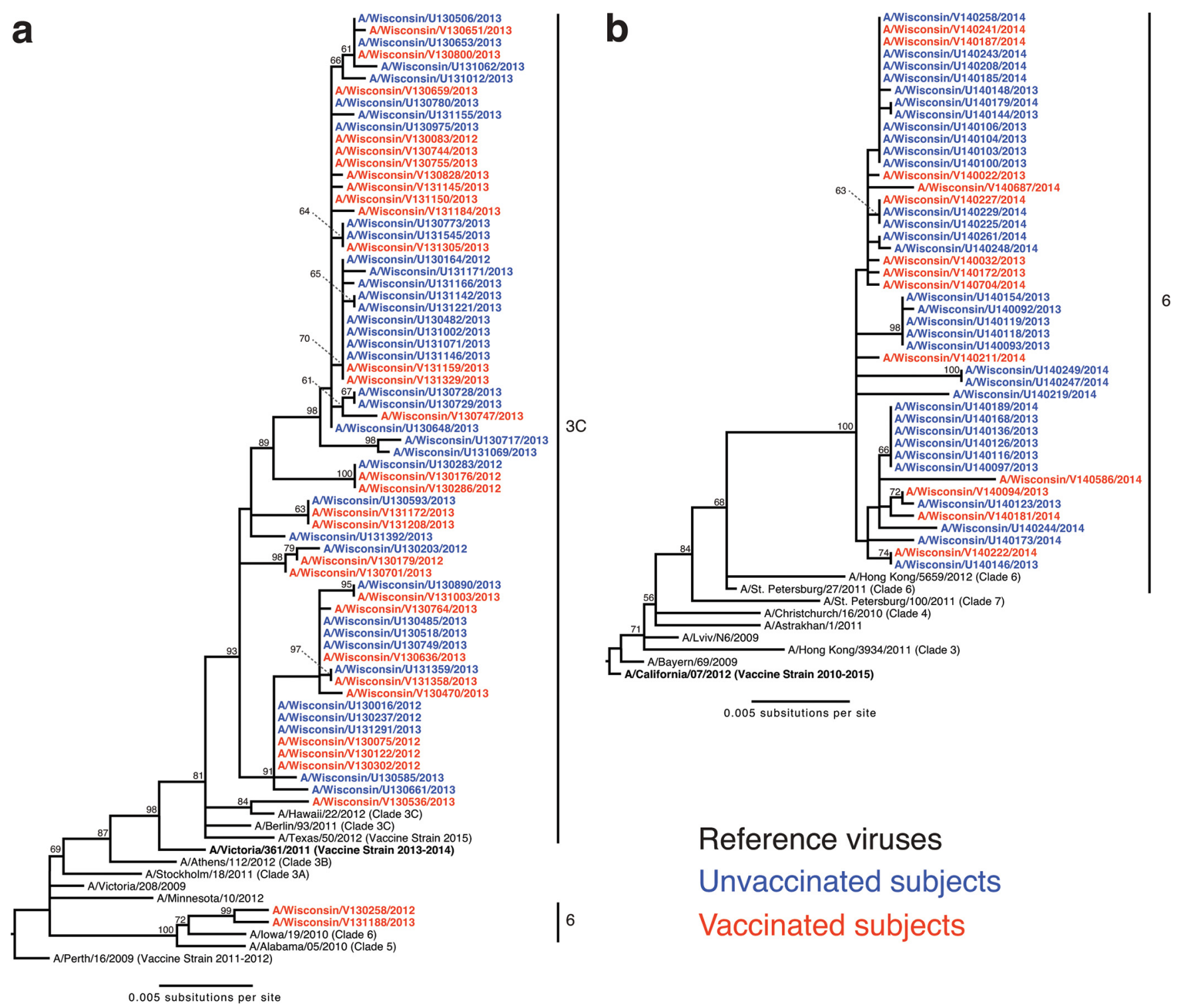

FIG 1 Phylogenetic relationships of influenza A viruses infecting nonvaccinated and vaccinated subjects in Marshfield, WI. (a) H3N2 phylogenetic tree constructed using 68 hemagglutinin genes from subjects infected during the 2012-13 season and 11 outgroup sequences representing WHO-recommended vaccine strains and representative H3N2 taxonomic clades (alignment length, 1,641 nucleotides). (b) H1N1pdm phylogenetic tree constructed using 46 hemagglutinin genes from subjects infected during the 2013-14 season and nine outgroup sequences representing WHO-recommended vaccine strains and representative H1N1pdm taxonomic clades (alignment length, 1,698 nucleotides). Bootstrap values were determined from 1,000 replicates and are indicated above the corresponding nodes when values are above $50 \%$.

ilarly, $\pi_{\mathrm{S}}$, describes the frequency of silent mutations within a virus population. Note that these statistics describe the genetic diversity of viral populations within a single host and do not rely on an external reference sequence. Comparing the values of these statistics for a given gene provides information about the "direction" of natural selection. Generally, a $\pi_{\mathrm{N}} / \pi_{\mathrm{S}}$ ratio of $>1$ indicates that positive selection is favoring genetic diversification. In contrast, a $\pi_{\mathrm{N}} / \pi_{\mathrm{S}}$ ratio of $<1$ indicates that purifying (or negative) selection is acting to maintain a fit virus population by removing deleterious mutations. Comparing $\mathrm{HA} \pi_{\mathrm{N}}$ and $\pi_{\mathrm{S}}$ in vaccinated and nonvaccinated subjects thus allows us to determine whether overall HA genetic diversity is different in these two groups and also may indicate whether differences in diversity are due to nat- ural selection acting on HA. We computed $\pi_{\mathrm{N}}$ and $\pi_{\mathrm{S}}$ for the full-length HA coding region and also for HA1, HA2, and the receptor-binding domain (RBD) to account for the possibility that selection could act differently at these discrete functional domains of the HA gene.

We computed the overall mean $\pi_{\mathrm{N}}$ and $\pi_{\mathrm{S}}$ values for $\mathrm{H} 3 \mathrm{~N} 2$ ( $n=68)$ and H1N1pdm $(n=46)$ viruses. Mean $\pi_{\mathrm{N}}$ and $\pi_{\mathrm{S}}$ values for each region varied widely (Table 2). For example, individual means of $\pi_{\mathrm{N}}$ for full-length HA genes ranged from 0.00040 to 0.00281 substitutions per site for $\mathrm{H} 3 \mathrm{~N} 2$ viruses and from 0.00035 to 0.00108 substitutions per site for H1Nlpdm. We found that overall mean $\pi_{\mathrm{N}}$ was lower than $\pi_{\mathrm{S}}$ at each HA domain for all viruses (Tables 2 and 3; two-tailed $P<0.0001$ to 0.05 ; Student $t$ 
TABLE 2 Estimates of nonsynonymous and synonymous nucleotide diversity for hemagglutinin genes of influenza A viruses ${ }^{a}$

\begin{tabular}{|c|c|c|c|c|c|c|c|}
\hline \multirow{2}{*}{$\begin{array}{l}\text { Subtype } \\
\text { and } \\
\text { domain }\end{array}$} & \multicolumn{3}{|l|}{$\pi_{\mathrm{N}}$} & \multicolumn{3}{|l|}{$\pi_{\mathrm{S}}$} & \multirow[b]{2}{*}{$\begin{array}{l}\pi_{\mathrm{N}} \text { Vs } \\
\pi_{\mathrm{S}}(P)\end{array}$} \\
\hline & $\begin{array}{l}\pi_{\mathrm{N}} \\
\left(10^{-3}\right)\end{array}$ & SEM & $\begin{array}{l}\text { Range } \\
\left(10^{-3}\right)\end{array}$ & $\begin{array}{l}\pi_{\mathrm{S}} \\
\left(10^{-3}\right)\end{array}$ & SEM & $\begin{array}{l}\text { Range } \\
\left(10^{-3}\right)\end{array}$ & \\
\hline \multicolumn{8}{|l|}{$\mathrm{H} 3 \mathrm{~N} 2$} \\
\hline HA & 0.69 & 0.04 & $0.40-2.81$ & 1.24 & 0.19 & $0.51-13.48$ & 0.0053 \\
\hline HA1 & 0.70 & 0.04 & $0.39-2.61$ & 1.16 & 0.15 & $0.32-9.68$ & 0.0036 \\
\hline HA2 & 0.68 & 0.05 & $0.39-3.42$ & 1.47 & 0.38 & $0.36-26.42$ & 0.0412 \\
\hline RBD & 0.76 & 0.06 & $0.36-4.44$ & 1.38 & 0.21 & $0.29-13.33$ & 0.0052 \\
\hline \multicolumn{8}{|c|}{ H1N1pdm } \\
\hline HA & 0.60 & 0.02 & $0.35-1.08$ & 1.07 & 0.11 & $0.33-3.82$ & 0.0001 \\
\hline HA1 & 0.61 & 0.03 & $0.32-1.35$ & 0.96 & 0.10 & $0.28-3.15$ & 0.0012 \\
\hline HA2 & 0.59 & 0.03 & $0.33-1.06$ & 1.25 & 0.17 & $0.34-4.99$ & 0.0002 \\
\hline RBD & 0.56 & 0.03 & $0.26-1.00$ & 0.99 & 0.12 & $0.24-3.92$ & 0.0008 \\
\hline
\end{tabular}

${ }^{a} \pi_{\mathrm{N}}$, nonsynonymous nucleotide diversity; $\pi_{\mathrm{S}}$, synonymous nucleotide diversity. $P$ values correspond to comparisons of mean $\pi_{\mathrm{N}}$ and $\pi_{\mathrm{S}}$ values at each HA gene domain. Statistical analysis performed using a Student $t$ test. Values for $\pi_{\mathrm{N}}, \pi_{\mathrm{S}}$, and ranges are presented as coefficients $\times 10^{-3}$ substitutions per site; e.g., a listed value of 0.69 equals $6.9 \times 10^{-4}$ substitutions per site.

tests), showing that HA genes are generally subject to purifying selection in these individuals.

We did not detect significant differences in nucleotide diversity between nonvaccinated and vaccinated subjects. The one exception to this trend was in the RBD domain of H1N1pdm viruses, in which $\pi_{N}$ was slightly but significantly greater in vaccinated than in nonvaccinated subjects $(P=0.016$; Table 3$)$. One might predict that within-host HA diversity would increase with time after in- fection, as random mutations accumulate, and potentially as antibody pressure favors the outgrowth of antigenic variants. In this case, we would expect that $\pi_{\mathrm{N}}$ and/or $\pi_{\mathrm{S}}$ values would increase with time after infection. However, we found no association between $\pi_{\mathrm{N}}$ or $\pi_{\mathrm{S}}$ values and the number of days after symptom onset for either H3N2 or H1N1pdm viruses (data not shown), suggesting that the day subjects presented to the clinic did not bias our observations. Overall, our data indicate that purifying selection was strong on both full-length HA segments and individual HA functional domains in both nonvaccinated and vaccinated subjects and that there was no significant reduction in HA genetic diversity in vaccinated versus nonvaccinated subjects.

Deep sequencing reveals $\mathrm{HA}$ genetic and potential antigenic diversity in humans. Finally, we asked whether any of the HA mutations we observed had the potential to encode antigenic diversity. To do this, we enumerated HA SNPs relative to various reference sequences (Fig. 2). We only considered SNPs if they were detected above our experimentally defined cutoff of $\geq 1 \%$ of sequence reads in a sample (20). In total, we detected 695 nonsynonymous and 875 synonymous SNPs from individuals infected with $\mathrm{H} 3 \mathrm{~N} 2$ viruses; in $\mathrm{H} 1 \mathrm{~N} 1 \mathrm{pdm}$-infected individuals, we detected 700 nonsynonymous SNPs and 735 synonymous SNPs (Table 4). The SNP frequency spectrum had a bimodal distribution, with most mutations detected either at low frequency ( 1 to $10 \%$ of sequences) or at high frequency ( 90 to $100 \%$ of sequences, Fig. 2). Overall, the average number of SNPs relative to vaccine strains in each host was significantly greater for H1N1pdm viruses (nonsynonymous SNPs, $14.8 \pm 3.2$; synonymous SNPs, $16.0 \pm 3.1)$ than $\mathrm{H} 3 \mathrm{~N} 2$ viruses (nonsynonymous SNPs, $10.2 \pm 2.4$; synonymous SNPs, $12.9 \pm 3.8$ [two-tailed $P>0.0001$, Student $t$ test]). This

TABLE 3 Estimates of nonsynonymous and synonymous nucleotide diversity in nonvaccinated and vaccinated subjects ${ }^{a}$

\begin{tabular}{|c|c|c|c|c|c|c|c|}
\hline \multirow[b]{2}{*}{ Subtype and domain } & \multicolumn{3}{|c|}{ Nonvaccinated } & \multicolumn{3}{|l|}{ Vaccinated } & \multirow[b]{2}{*}{$P$} \\
\hline & $\pi_{\mathrm{N}}\left(10^{-3}\right)$ & SEM & Range $\left(10^{-3}\right)$ & $\pi_{\mathrm{N}}\left(10^{-3}\right)$ & SEM & Range $\left(10^{-3}\right)$ & \\
\hline \multicolumn{8}{|l|}{ H3N2 } \\
\hline HA1 & 0.72 & 0.06 & $0.41-2.61$ & 0.68 & 0.03 & $0.39-1.25$ & 0.576 \\
\hline HA2 & 0.73 & 0.08 & $0.39-3.42$ & 0.62 & 0.03 & $0.42-1.44$ & 0.235 \\
\hline RBD & 0.81 & 0.11 & $0.43-4.44$ & 0.70 & 0.04 & $0.36-1.17$ & 0.385 \\
\hline $\mathrm{HA}$ & 0.58 & 0.03 & $0.35-1.08$ & 0.67 & 0.04 & $0.38-0.90$ & 0.094 \\
\hline HA1 & 0.59 & 0.04 & $0.32-1.35$ & 0.66 & 0.05 & $0.36-0.94$ & 0.316 \\
\hline HA2 & 0.56 & 0.03 & $0.33-0.96$ & 0.67 & 0.05 & $0.36-1.06$ & 0.056 \\
\hline RBD & 0.52 & 0.03 & $0.26-1.00$ & 0.66 & 0.05 & $0.42-0.97$ & 0.016 \\
\hline Subtype and domain & $\pi_{\mathrm{S}}\left(10^{-3}\right)$ & SEM & Range $\left(10^{-3}\right)$ & $\pi_{\mathrm{S}}\left(10^{-3}\right)$ & SEM & Range $\left(10^{-3}\right)$ & $P$ \\
\hline RBD & 1.58 & 0.37 & $0.29-13.33$ & 1.13 & 0.15 & $0.46-5.18$ & 0.296 \\
\hline \multicolumn{8}{|l|}{ H1N1pdm } \\
\hline $\mathrm{HA}$ & 1.10 & 0.16 & $0.33-3.82$ & 0.99 & 0.10 & $0.47-1.91$ & 0.665 \\
\hline HA1 & 0.99 & 0.14 & $0.28-3.15$ & 0.88 & 0.06 & $0.41-1.28$ & 0.614 \\
\hline HA2 & 1.28 & 0.23 & $0.34-4.99$ & 1.17 & 0.23 & $0.43-3.48$ & 0.774 \\
\hline RBD & 1.01 & 0.17 & $0.24-3.92$ & 0.95 & 0.13 & $0.34-2.28$ & 0.827 \\
\hline
\end{tabular}

${ }^{a} \pi_{\mathrm{N}}$, nonsynonymous nucleotide diversity; $\pi_{\mathrm{S}}$, synonymous nucleotide diversity. $P$ values correspond to comparisons of mean $\pi_{\mathrm{N}}$ and $\pi_{\mathrm{N}}$ or of $\pi_{\mathrm{S}}$ and $\pi_{\mathrm{S}}$ values for each HA gene domain (values were compared horizontally). Statistical analysis performed using a Student $t$ test. 


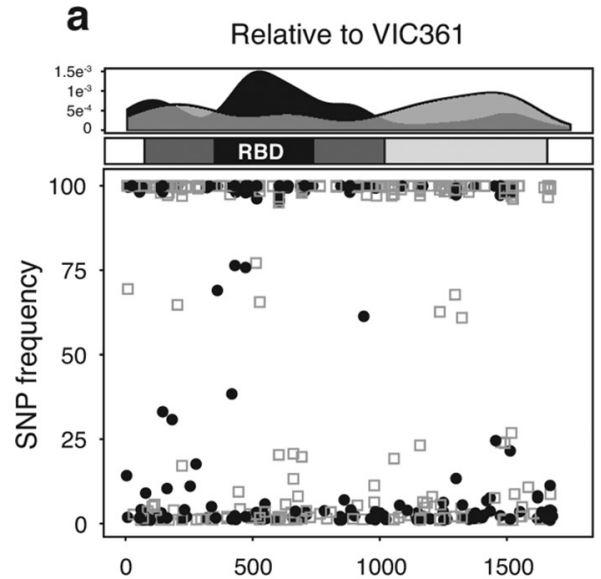

b

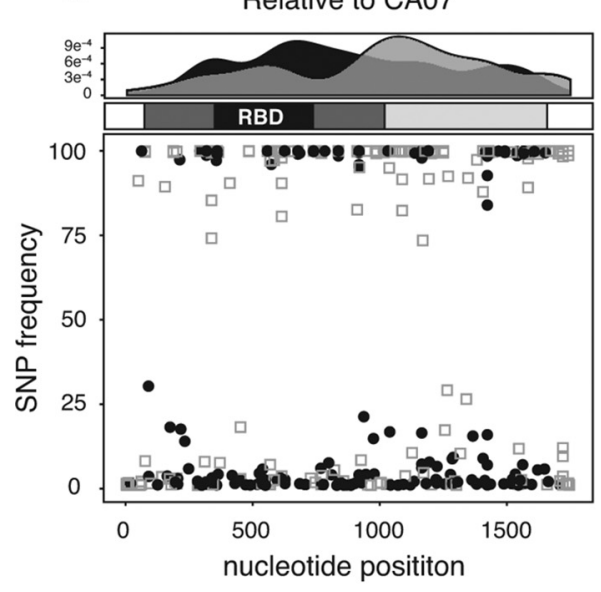

C
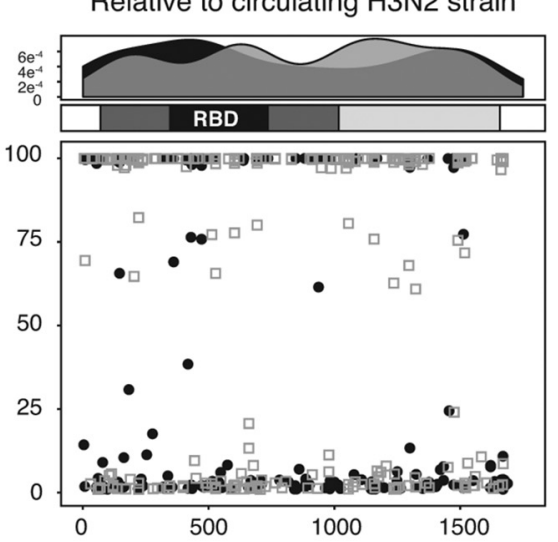

d Relative to circulating $\mathrm{H} 1 \mathrm{~N} 1 \mathrm{pdm}$ strain

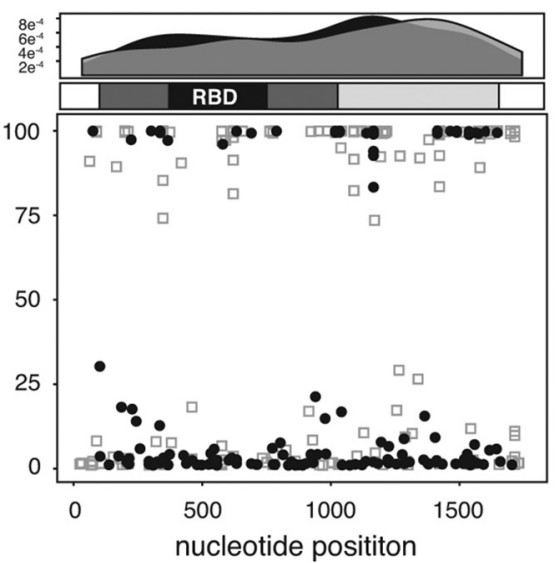

e Relative to autologus consensus
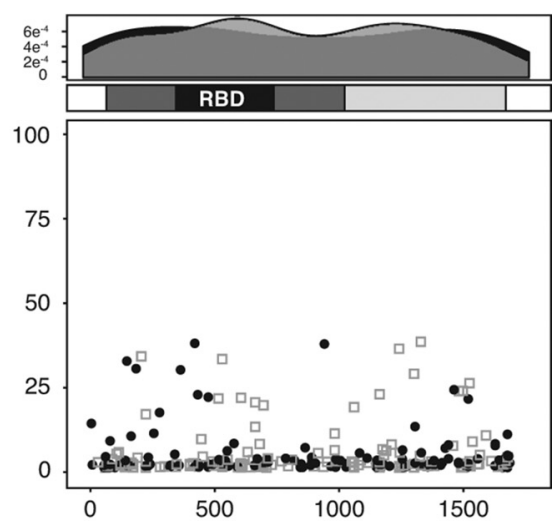

f

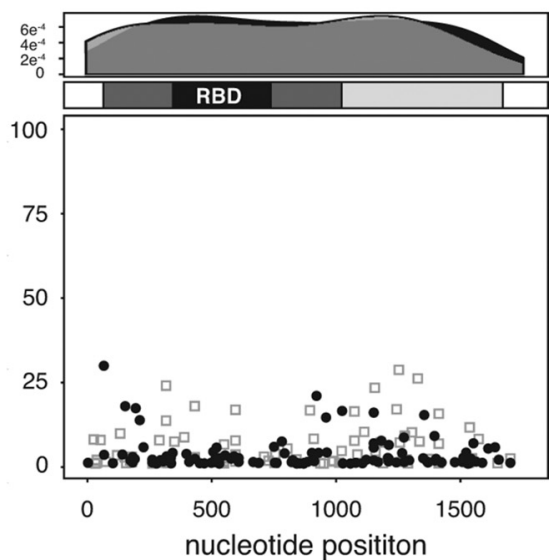

nonsynonymous $\square$ synonymous

FIG 2 Deep sequencing reveals sequence variation in hemagglutinin genes during human infection. We used deep sequencing to reveal the within-host viral variation from nonvaccinated and vaccinated subjects. Displayed are SNPs detected in H3N2-infected (a, c, and e) and H1N1pdm-infected (b, d, and f) subjects. All sequence reads were mapped against three reference sequences: a vaccine strain, the most abundantly detected HA gene sequence, and against each sample's own autologous consensus sequence. Black circles represent nonsynonymous mutations, and gray squares represent synonymous mutations. The $x$ axis represents the nucleotide position, and the $y$ axis represents the frequency for which each mutation was detected from human biological samples. Above each SNP frequency plot is a cartoon depiction of the linear HA gene with shaded functional domains: HA1 (dark gray), HA2 (light gray), and the receptor-binding domain (RBD, black). Density plots indicate the likelihood for a nonsynonymous (black) or synonymous (gray) SNP to occur, regardless of frequency, in a given position across the HA gene.

greater genetic distance between vaccine and circulating strains for H1N1pdm viruses may be due to the fact that $\sim 5$ years elapsed between emergence of the CA07 vaccine strain in 2009 and the 2013-14 influenza season evaluated here, whereas only $\sim 1$ year separated the emergence of Vic361 and the 2012-13 season. Consistent with this observation, the density of nonsynonymous SNPs was greatest in the HA RBD for both H1N1pdm and H3N2 viruses (Fig. 2a and b, top panels). The elevated density of nonsynonymous variants in RBD is only observed when vaccine strains are used as reference sequences, and disappears when SNPs are defined with respect to consensus sequences from the relevant season or from within our subjects (Fig. 2c to f, top panels). Note that our analyses of diversity and selection presented in Tables 2 and 3 above did not use reference sequences and are therefore not affected by these observations.

To identify mutations with the potential to alter influenza antigenicity, we queried SNP data for mutations that lay in previ-
TABLE 4 Summary of nonsynonymous and synonymous mutations detected in our study ${ }^{a}$

\begin{tabular}{|c|c|c|c|c|c|c|}
\hline \multirow{3}{*}{$\begin{array}{l}\text { Mutation } \\
\text { frequency }(\%)\end{array}$} & \multicolumn{6}{|c|}{ No. of mutations } \\
\hline & \multicolumn{3}{|c|}{$\begin{array}{l}\mathrm{H} 3 \mathrm{~N} 2-2012 / 13 \\
(n=68)\end{array}$} & \multicolumn{3}{|c|}{$\begin{array}{l}\text { H1N1pdm-2013/14 } \\
(n=46)\end{array}$} \\
\hline & $\mathrm{N}$ & $S$ & $\mathrm{~N}+\mathrm{S}$ & $\mathrm{N}$ & $S$ & $\mathrm{~N}+\mathrm{S}$ \\
\hline $1-10$ & 97 & 84 & 181 & 100 & 64 & 164 \\
\hline $10-20$ & 6 & 6 & 12 & 9 & 6 & 15 \\
\hline $20-30$ & 2 & 6 & 8 & 1 & 2 & 3 \\
\hline $30-40$ & 3 & 0 & 3 & 1 & 0 & 1 \\
\hline $40-50$ & 0 & 0 & 0 & 0 & 0 & 0 \\
\hline $50-60$ & 0 & 0 & 0 & 0 & 0 & 0 \\
\hline $60-70$ & 2 & 6 & 8 & 0 & 0 & 0 \\
\hline $70-80$ & 2 & 1 & 3 & 0 & 2 & 2 \\
\hline $80-90$ & 0 & 0 & 0 & 1 & 7 & 8 \\
\hline $90-100$ & 583 & 772 & 1,355 & 588 & 654 & 1,242 \\
\hline Total & 695 & 875 & 1,570 & 700 & 735 & 1,435 \\
\hline
\end{tabular}

${ }^{a} \mathrm{~N}$, nonsynonymous; $\mathrm{S}$, synonymous. 
TABLE 5 Single-nucleotide polymorphisms detected in antigenicity-associated HA positions from infected humans ${ }^{a}$

\begin{tabular}{|c|c|c|c|c|c|c|c|}
\hline $\begin{array}{l}\text { Subtype and } \\
\text { nucleotide position }\end{array}$ & $\begin{array}{l}\text { Nucleotide } \\
\text { change }\end{array}$ & $\begin{array}{l}\mathrm{H} 3 \text { amino acid } \\
\text { residue no. }\end{array}$ & $\begin{array}{l}\text { Amino acid } \\
\text { change }\end{array}$ & $\begin{array}{l}\text { Antigenic } \\
\text { site }\end{array}$ & $\begin{array}{l}\text { No. of } \\
\text { subjects }\end{array}$ & $\begin{array}{l}\text { Frequency } \\
\text { range }(\%)\end{array}$ & $\begin{array}{l}\text { Detected in 2014-15 } \\
\text { influenza season }\end{array}$ \\
\hline \multicolumn{8}{|l|}{ H3N2 } \\
\hline 205 & $\mathrm{G} \rightarrow \mathrm{A}$ & 53 & $\mathrm{D} \rightarrow \mathrm{N}$ & $\mathrm{C}$ & 2 & 100 & $0 / 155$ \\
\hline 472 & $\mathrm{~A} \rightarrow \mathrm{G}$ & 142 & $\mathrm{R} \rightarrow \mathrm{G}$ & A & 19 & $2.1-100$ & $31 / 155$ \\
\hline 472 & $\mathrm{AG} \rightarrow \mathrm{GA}$ & 143 & $\mathrm{R} \rightarrow \mathrm{E}$ & A & 1 & 2.0 & $0 / 155$ \\
\hline 515 & $\mathrm{AA} \rightarrow \mathrm{GC}$ & 156 & $\mathrm{Q} \rightarrow \mathrm{R}$ & B & 1 & 3.3 & $0 / 155$ \\
\hline 516 & $\mathrm{~A} \rightarrow \mathrm{C}$ & 156 & $\mathrm{Q} \rightarrow \mathrm{H}$ & B & 68 & $96.1-100$ & $155 / 155$ \\
\hline 706 & $\mathrm{~A} \rightarrow \mathrm{G}$ & 220 & $\mathrm{R} \rightarrow \mathrm{G}$ & $\mathrm{D}$ & 2 & $2.9-3.5$ & $0 / 155$ \\
\hline 882 & $\mathrm{~T} \rightarrow \mathrm{G}$ & 278 & $\mathrm{~N} \rightarrow \mathrm{K}$ & $\mathrm{C}$ & 66 & 100 & $150 / 155$ \\
\hline \multicolumn{8}{|l|}{ H1N1pdm } \\
\hline 283 & $\mathrm{C} \rightarrow \mathrm{A}$ & 80 & $\mathrm{~S} \rightarrow \mathrm{Y}$ & $\mathrm{Cb}$ & 1 & 1.4 & NA \\
\hline 283 & $\mathrm{C} \rightarrow \mathrm{T}$ & 80 & $\mathrm{~S} \rightarrow \mathrm{F}$ & $\mathrm{Cb}$ & 1 & 2.2 & NA \\
\hline 550 & $\mathrm{~A} \rightarrow \mathrm{G}$ & 163 & $\mathrm{~K} \rightarrow \mathrm{R}$ & $\mathrm{Sa}$ & 2 & $1.0-2.5$ & NA \\
\hline 558 & $\mathrm{~A} \rightarrow \mathrm{C}$ & 183 & $\mathrm{~K} \rightarrow \mathrm{Q}$ & $\mathrm{Cal}$ & 45 & 100 & NA \\
\hline
\end{tabular}

${ }^{a}$ Antigenic sites refer to defined HA protein sites important for the recognition of neutralizing antibodies $(7,8)$. The number of subjects signifies the total number of individuals (nonvaccinated and vaccinated) for which a particular nucleotide change was observed (H3N2, $n=68$; H1N1pdm, $n=46$ ). The frequency range indicates the minimum and maximum frequency that a particular nucleotide change was observed in our cohort.

${ }^{b}$ That is, the proportion of individual "antigenic ridge" mutations found in publically available H3N2 HA sequences from the 2014-15 influenza season in the United States. No H1N1pdm HA sequences were deposited for the 2014-15 influenza seasons from the United States (indicated as not applicable [NA]). A complete summary of each amino acid polymorphisms is available upon request.

ously defined antigenic sites. Nonsynonymous mutations occurred in our subjects in $9 \mathrm{HA}$ amino acid positions in $\mathrm{H} 3 \mathrm{~N} 2$ and $8 \mathrm{HA}$ amino acid positions in H1N1pdm located at or near the receptor binding pocket, which were previously found to affect viral antigenicity (Table 5 and Fig. 3). Notably, we found substitutions in HA amino acid position 156 in $\mathrm{H} 3 \mathrm{~N} 2$ viruses (Q156H/R) and positions 158 and 159 of H1N1pdm viruses (G158E and N159K), all of which lie in the "antigenic ridge" of the HA protein (H3 numbering used throughout). The antigenic ridge is a span of residues on the periphery of the receptor-binding site previously shown to be responsible for antigenic change in $\mathrm{H} 3 \mathrm{~N} 2$ (12) and H1N1pdm viruses (13). An A $\rightarrow \mathrm{G}$ SNP at nucleotide 515 encoding a glutamine-to-histidine change at amino acid position 156 was detected at or near fixation all H3N2-infected subjects. This $\mathrm{Q} 156 \mathrm{H}$ substitution was associated with vaccine mismatch during the 2003-2004 influenza season and has been found in HA consensus sequences of circulating $\mathrm{H} 3 \mathrm{~N} 2$ viruses ever since (36). The $\mathrm{A} \rightarrow \mathrm{C}$ SNP encoding the glutamine-to-arginine substitution at amino acid position 156 was detected in a single vaccinated subject (V130083) in 3.3\% of viral sequences. The Q156R mutation was previously linked to egg adaptation of the 2012-2014 Vic361 vaccine virus (37). The Q156R mutation was not found in any of 155 publically available consensus sequences generated from the 2014-15 influenza season in the United States (Table 5). Outside the antigenic ridge, we detected an $\mathrm{A} \rightarrow \mathrm{G}$ SNP at nucleotide position 472 that encoded an arginine-to-glutamate substitution at amino acid position 142 . If detected, the R142G mutation was found at or near fixation ( $\geq 98 \%$ ) in the virus population. However, we did detect the R142G substitution in $2.1 \%$ of viral sequences in subject U130482. Our data do not allow us to determine why $\mathrm{R} 142 \mathrm{G}$ is present at such low frequency in this individual, when it is the dominant variant in viruses infecting other subjects in the cohort. Mutations at position 142 have been documented to confer changes to antibody binding (38), and in recent years codon 142 has toggled between encoding arginine and glycine in circulating H3N2 viruses (39). We therefore speculate that this site is likely varying under immune pressure.

In $\mathrm{H} 1 \mathrm{~N} 1 \mathrm{pdm}$ viruses, we detected a $\mathrm{G} \rightarrow \mathrm{A}$ SNP at nucleotide 535 encoding a glycine-to-glutamate substitution at amino acid position 158 in 2.3 and $2.4 \%$ of viral sequences in U140225 and V140227, respectively. G158E is detected in consensus H1N1pdm HA sequences in the Influenza Research Database (40) but only in $0.65 \%(n=4,001)$ of samples. Interestingly, viruses with the G158E substitution replicated in vitro in the presence of H1N1pdm-specific ferret antibodies (41). A T $\rightarrow$ A SNP encoding an asparagine-to-lysine substitution at position 159 was detected in three H1N1pdm-infected subjects at low frequencies: V14022 at $1.4 \%, \mathrm{~V} 140172$ at $2.2 \%$, and $\mathrm{U} 14106$ at $5.7 \%$ of viral sequences. In a previous study, H1N1pdm viruses bearing the N159K substitution (N156K in $\mathrm{H} 1$ numbering) outcompeted wild-type viruses in tissue culture, replicated efficiently in H1N1pdm immunized ferrets, and were efficiently transmitted among animals (42). Interestingly, despite causing escape from H1N1pdm-specific antibodies in vitro and in vivo in ferret studies, this mutation is found at the consensus level in a minority of viruses that previously circulated in humans $(0.1 \%$ of sequences; $n=4,001)$. Taken together, these data show that mutations with the potential to encode antigenic variation are generated in humans naturally infected with influenza viruses. Unfortunately, because serum samples from these subjects were not available, we were not able to assess the impact of these mutations on autologous antibody rec- 

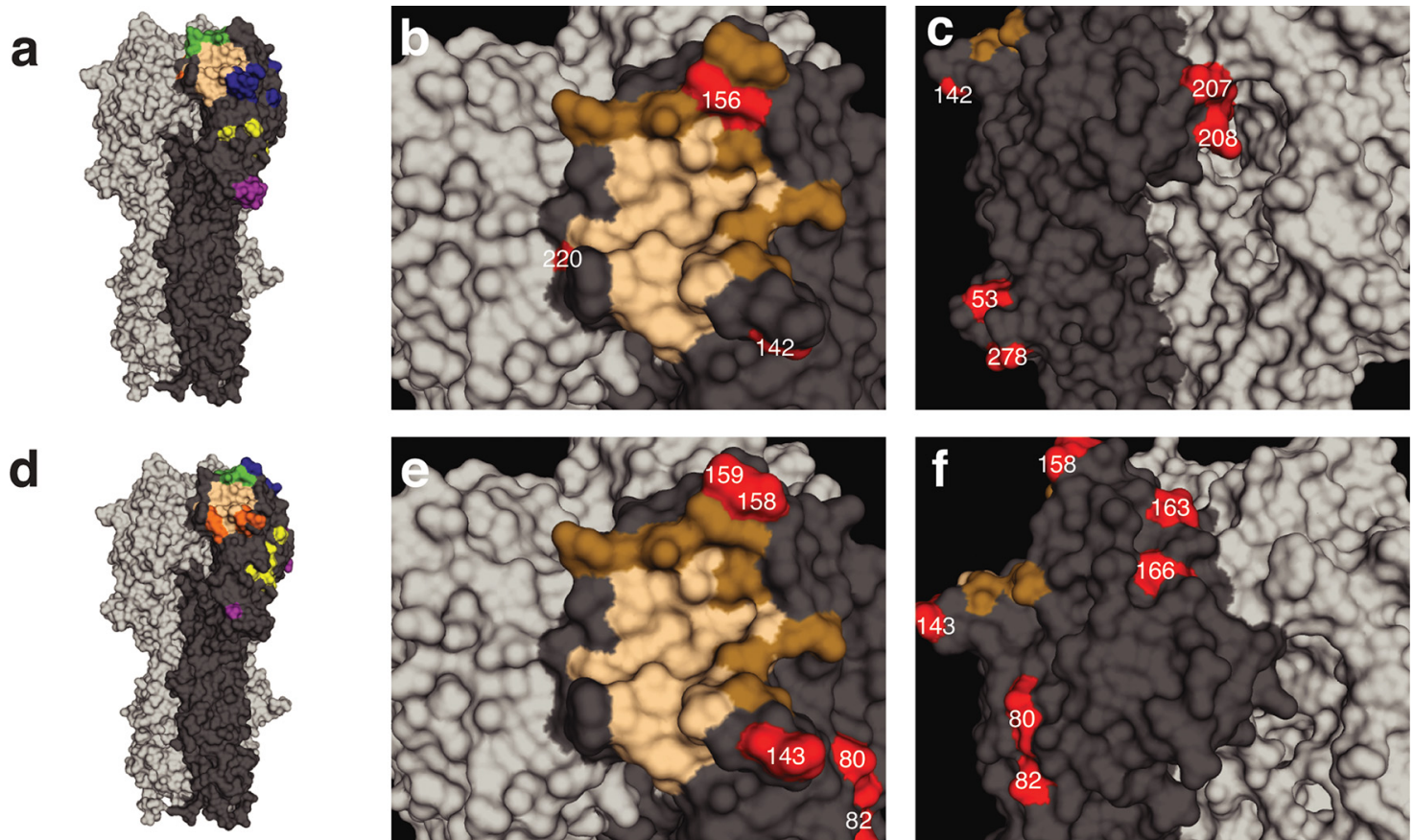

FIG 3 Localization of amino acid substitutions identified in this study on the HA structure. The structure of an A/Aichi/2/1968 HA trimer (Protein Data Bank accession 5HMG) (53) is shown. The three monomers are shown in black and gray with the receptor-binding site in light brown, and positions previously defined as responsible for antigenic cluster transitions are shown in dark brown (12). Mutations detected in human subjects infected with H3N2 and H1N1pdm viruses are shown in red. All mutations are shown in $\mathrm{H} 3$ numbering. (a) H3N2 antigenic sites, as defined by Wiley et al. (8); antigenic sites A to E are shown in blue, green, magenta, orange, and yellow, respectively. (b and c) Mutations detected in subjects infected with H3N2 viruses. (d) H1N1 antigenic sites, as defined by Caton et al. (9); antigenic sites Sa, Sb, Ca1, Ca2, and Cb are shown in blue, green, magenta, orange and yellow, respectively. (e and f) Mutations detected in subjects infected with H1N1pdm viruses. Images were created with MacPymol (http://www.pymol.org/).

ognition. These mutations exist well below the detection limit of Sanger sequencing in our subjects and are only rarely detected at the consensus level in humans.

\section{DISCUSSION}

Although influenza viruses are known to exist as a genetically diverse population within an infected host, the potential impact of this diversity on viral adaptation to immune selection is not well understood. Here, we characterized influenza HA genes directly from human clinical specimens and evaluated the contribution of HA within-host genetic variation to vaccine failure, as well as the potential ways in which vaccine-induced immunity shapes within- and between-host diversity. Influenza viruses infecting nonvaccinated and vaccinated subjects in our study were genetically similar and did not display patterns of sequence diversity consistent with the selection of antigenic variants within any individual host. Within-host HA genetic diversity in both nonvaccinated and vaccinated subjects consists of more synonymous diversity than nonsynonymous diversity, suggesting that most mutations are deleterious and purifying selection is the dominant evolutionary force affecting HA in this cohort. Interestingly, we observed several nonsynonymous mutations below the detection threshold of Sanger sequencing in both $\mathrm{H} 3 \mathrm{~N} 2$ and $\mathrm{H} 1 \mathrm{~N} 1 \mathrm{pdm}$ viruses located in positions that can cause significant antigenic change. Moreover, several low-frequency nonsynonymous mutations were detected reproducibly in multiple subjects, in both nonvaccinated and vaccinated groups. This observation raises the possibility that antigenic variants are frequently generated during influenza virus infection in humans, but that they often do not become fixed in the viral population even when they would be expected to have a strong fitness advantage.

There are important caveats to the interpretation of our results. First, we initially compared HA gene sequences from nonvaccinated and vaccinated subjects to identify potential mutations associated with vaccine failure. Humans have highly variable preexisting immune repertoires against influenza, which are shaped by individual infection and vaccination histories, as well as by age, comorbidities, and host genetics (41, 43-45). Grouping virus sequences purely by same-season vaccine status may not adequately capture important biological differences among these subjects. When possible, it would be desirable to use immunological characteristics (e.g., hemagglutination inhibition titers) to stratify subjects into more biologically relevant groups; unfortunately, that was not possible for our cohort. Second, because autologous serum was not available, we do not know whether putative antigenic variants specifically escape antibodies present in the subjects in which the variants were detected. However, past reports have shown that Q156H/R (H3N2) impacts antigenicity of vaccine strains, and G158E and N159K (H1N1pdm) confer escape from H1N1pdm-specific antibodies in vitro and in vivo.

Our findings indicated that within-host HA genetic diversity and HA consensus sequences were similar between nonvaccinated and vaccinated subjects. It is likely that virtually all of these subjects had some degree of preexisting immunity to influenza due to previous infection and/or vaccination, and as a result, mutations that confer escape from antibodies in experimental animals may not be as effective in humans. To the extent that the mutations we 
describe here represent bona fide antigenic changes, we cannot explain why antibody escape mutants have not emerged at the consensus level using sequence data alone. However, we speculate that for antigenic variants to reach fixation in the virus population, compensatory mutations may be needed to enhance viral replicative fitness before the antigenic variant is lost by purifying selection. In accord with our observations, a previous study showed that prior immunity had little effect on the level and structure of genetic diversity of influenza viruses infecting vaccinated horses (46). In that study, Murcia et al. speculated that purifying selection (i.e., more synonymous diversity relative to nonsynonymous diversity) is the dominant signal of influenza within individual hosts (46); this is consistent with the idea that influenza viruses are well adapted to replication and transmission in their natural hosts, and therefore most mutations are likely to be deleterious. Indeed, mutations that alter HA antigenicity may frequently exact a fitness cost that requires compensatory mutations to restore viral replicative capacity (47). Finally, because each subject was sampled only once, we could not follow the changing frequencies of SNPs with time to detect potential positive selection at individual sites. Approaches using time-series samples enable better detection of site-specific positive selection (48).

From 1968 to 201114 antigenic clusters of H3N2 viruses have emerged, each cluster being replaced by viruses with distinct antigenic characteristics (11). Single amino acid substitutions, restricted to seven positions $(145,155$ to 159,189 , and 193) on the HA protein, were responsible for antigenic cluster transitions during the evolution of H3N2 viruses from 1968 to 2003 (13). One mutation detected in $\mathrm{H} 3 \mathrm{~N} 2$ viruses in our study, encoding Q156H, fell within this defined "antigenic ridge." A Q156H substitution was responsible for the Sydney-1997 to Fujian-2002 antigenic cluster transition during the 2003-04 season, resulting in vaccine mismatch $(12,36)$. Acquisition of a glutamine $(\mathrm{Q})$ at HA position 156 during egg passage of vaccine seed stocks was also associated with low vaccine effectiveness against $\mathrm{H} 3 \mathrm{~N} 2$ viruses in the 2012-13 season (49). Contemporary H3N2 strains in circulation possess a histidine at HA position 156 in publically available consensus sequences; however, we found that $3.3 \%$ of sequences within a single vaccinated case (V130083) possessed a Q156R substitution. Acquisition of arginine at position 156 has been previously linked to egg adaptation of the initial egg-grown A/Victoria/ 361/2011 wild-type virus for the production of the 2012-13 and 2013-14 vaccines (37). However, the impact of Q156R on recognition of antibodies raised by vaccines encoding glutamine at position 156 has yet to be evaluated in vitro or in animal models.

The overwhelming majority of isolated H1N1pdm viruses remain antigenically similar to the prototypical A/California/07/ 2007 vaccine virus (50). In the HA protein of H1N1pdm viruses, substitutions in amino acid positions 154 to 162 (H3 numbering) located adjacent to the receptor-binding site can cause escape from human infant and ferret antibodies after H1N1pdm virus infection (i.e., $\geq 4$-fold reduction in HI titer) (13). We detected a G158E substitution in a nonvaccinated case and a vaccinated case in 2.3 and $2.4 \%$ of sequences, respectively. The G158E substitution considerably alters the electrostatic properties which may be important for surface interactions between the HA protein and antibodies (41), changing the antigenic properties of H1N1pdm viruses as mapped by human monoclonal antibodies $(13,51)$ and by polyclonal antibodies in ferrets $(13,41,42)$. In three humans, one nonvaccinated and two vaccinated, we detected an N159K substitution at a low frequency. The N159K mutation has been described as affecting the local electrostatic charge potential of the HA protein (42). In a ferret model, the N159K mutation was found to confer escape from H1N1pdm-specific antibodies elicited by suboptimal vaccination (42). Viruses with the N159K mutation remained fit in a ferret transmission model and outcompeted the wild-type virus. During replication in ferrets, N159K variant viruses acquired additional mutations in $\mathrm{HA}$ and other gene segments. Interestingly, when the N159K mutant virus was generated by reverse genetics using backbones from A/Puerto Rico/8/1934 (H1N1) and A/Perth/261/2009 (H1N1pdm), it could not be rescued as a pure population, demonstrating that additional mutations not in the reverse genetic virus must be acquired to restore fitness. Furthermore, because a pure population of N159K virus was not recovered, escape from adult human antisera could not be tested (42). In another study, Koel et al. introduced different substitutions at position $159(\mathrm{~N} \rightarrow \mathrm{D}, \mathrm{N} \rightarrow \mathrm{G}, \mathrm{N} \rightarrow \mathrm{Y}$, and $\mathrm{N} \rightarrow \mathrm{S}$ ) and found that this position was important for antigenic change of H1N1pdm viruses, as measured against both human and ferret sera (13).

The ways in which influenza viruses evolve antigenically at the population level have been the subject of intense study in the past decade $(10-12,52)$. However, new antigenic variants are initially generated and selected at the level of individual infected hosts. Here, we showed that influenza virus populations infecting individual humans possess potential antigenic variation at low frequency. We previously showed that even very low-frequency influenza viral variants can pass through selective bottlenecks and be transmitted to new hosts via the airborne route. It is therefore possible that low-frequency putative antigenic variants we observed here could be transmitted via respiratory droplets. The use of Sanger sequencing for influenza surveillance typically defines consensus sequences and cannot resolve minority variants present below $20 \%$ of the viral population (18). Traditional Sanger sequencing could therefore miss potentially antigenic variants that occur in nature. The evolutionary mechanism by which antigenic variants are generated and selected for within individual hosts remains unclear. Our findings suggest that generating antigenic variants through mutation alone may not be sufficient for the emergence of new antigenic variants within a host. Instead, antigenic variants likely need compensatory mutations to restore replicative fitness, to avoid loss by genetic drift, and to be transmitted to new hosts to successfully emerge in nature. Additional studies are needed to more fully define the molecular basis of antigenic change and, perhaps more importantly, to determine the impact of antigenic changes on viral fitness and the evolutionary pathways by which fitness is restored in antigenic variants.

\section{ACKNOWLEDGMENTS}

We acknowledge Jennifer King, Huong McLean, and Maria Sundaram for their outstanding support of this study and thoughtful scientific discussion. We gratefully acknowledge the authors and originating and submitting laboratories of the sequences used in this study.

This study was supported by the Centers for Disease Control and Prevention through a cooperative agreement (U01 IP000471) awarded to E.A.B. and by a supplement to the WNPRC base grant (NIH P51 RR000167/OD011106), awarded to T.C.F. J.M.D. was supported by the National Science Foundation Graduate Research Fellowship DGE0718123, and the National Academy of Sciences Ford Foundation Dissertation Fellowship. N.W.F. and L.H.M. were supported by NIH National Research Service Award T32 GM07215. O.O.F. was supported by the IBS- 
SRP summer research fellowship DBI-1063085. We gratefully thank the authors, originating, submitting laboratories of the WHO National Influenza Centre Russian Federation, WHO Collaborating Centre for Reference and Research on Influenza, U.S. Air Force School of Aerospace Medicine, Swedish Institute for Infectious Disease Control, Russian Academy of Medical Sciences, National Institute for Medical Research, Minnesota Department of Health, Hellenic Pasteur Institute, Government Virus Unit (China), Centers for Disease Control and Prevention for the following GISAID sequences: EPI278805, EPI358885, EPI360950, EPI408119, EPI326342, EPI376512, EPI307676, EPI326139, EPI408130, EPI232453, EPI319527, EPI320141, EPI239666, EPI390473, EPI326206, EPI280341, EPI239631, and EPI319590.

J.M.D., N.W.F., J.K.M., E.A.B., and T.C.F. designed the experiments. J.K.M. and E.A.B. coordinated and collected the biological samples used in this study. J.M.D., N.W.F., O.O.F., L.H.M., O.K.C. and J.P.M. performed the experiments, J.M.D., N.W.F., L.H.M., E.A.B., and T.C.F. analyzed the results. J.M.D., N.W.F., O.O.F., J.P.M., L.H.M., J.K.M., E.A.B., and T.C.F. wrote the manuscript.

\section{FUNDING INFORMATION}

HHS | National Institutes of Health (NIH) provided funding to Thomas C. Friedrich under grant number P51 OD011106. HHS | National Institutes of Health (NIH) provided funding to Nicholas W. Florek under grant number GM07215. HHS | National Institutes of Health (NIH) provided funding to Louise $\mathrm{H}$. Moncla under grant number GM07215. National Science Foundation (NSF) provided funding to Jorge Dinis under grant number DGE-0718123. National Science Foundation (NSF) provided funding to Omolayo O. Fatola under grant number DBI-1063085. HHS | Centers for Disease Control and Prevention (CDC) provided funding to Edward Belongia under grant number U01 IP000471.

\section{REFERENCES}

1. World Health Organization. 2014. Influenza. Fact sheet 211. Accessed 4 May 2015. World Health Organization, Geneva, Switzerland. http://www .who.int/mediacentre/factsheets/fs211/en/.

2. Osterholm MT, Kelley NS, Sommer A, Belongia EA. 2012. Efficacy and effectiveness of influenza vaccines: a systematic review and meta-analysis. Lancet Infect Dis 12:36-44. http://dx.doi.org/10.1016/S1473-3099(11) 70295-X.

3. McLean HQ, Thompson MG, Sundaram ME, Kieke BA, Gaglani M, Murthy K, Piedra PA, Zimmerman RK, Nowalk MP, Raviotta JM, Jackson ML, Jackson L, Ohmit SE, Petrie JG, Monto AS, Meece JK, Thaker SN, Clippard JR, Spencer SM, Fry AM, Belongia EA. 2014. Influenza vaccine effectiveness in the United States during 2012-2013: variable protection by age and virus type. J Infect Dis 211:1529-1540. http://dx.doi.org/10.1093/infdis/jiu647.

4. Flannery B, Thaker SN, Clippard J, Monto AS, Ohmit SE, Zimmerman RK, Nowalk MP, Gaglani M, Jackson ML, Jackson LA, Belongia EA, McLean HQ, Berman L, Foust A, Sessions W, Spencer S, Fry AM. 2014. Interim estimates of 2013-14 seasonal influenza vaccine effectiveness-United States, February 2014. MMWR Morb Mortal Wkly Rep 63:137-142.

5. Flannery B, Clippard J, Zimmerman RK, Nowalk MP, Jackson ML, Jackson LA, Monto AS, Petrie JG, McLean HQ, Belongia EA, Gaglani M, Berman L, Foust A, Sessions W, Thaker SN, Spencer S, Fry AM. 2015. Early estimates of seasonal influenza vaccine effectiveness-United States, January 2015. MMWR Morb Mortal Wkly Rep 64:10-15.

6. Hensley SE, Das SR, Bailey AL, Schmidt LM, Hickman HD, Jayaraman A, Viswanathan K, Raman R, Sasisekharan R, Bennink JR, Yewdell JW. 2009. Hemagglutinin receptor binding avidity drives influenza $A$ virus antigenic drift. Science 326:734-736. http://dx.doi.org/10.1126/science .1178258 .

7. Kryazhimskiy S, Dushoff J, Bazykin GA, Plotkin JB. 2011. Prevalence of epistasis in the evolution of influenza A surface proteins. PLoS Genet 7:e1001301. http://dx.doi.org/10.1371/journal.pgen.1001301.

8. Wiley DC, Wilson IA, Skehel JJ. 1981. Structural identification of the antibody-binding sites of Hong Kong influenza haemagglutinin and their involvement in antigenic variation. Nature 289:373-378. http://dx.doi .org/10.1038/289373a0.
9. Caton AJ, Brownlee GG, Yewdell JW, Gerhard W. 1982. The antigenic structure of the influenza virus $\mathrm{A} / \mathrm{PR} / 8 / 34$ hemagglutinin (H1 subtype). Cell 31:417-427. http://dx.doi.org/10.1016/0092-8674(82)90135-0.

10. Smith DJ, Lapedes AS, de Jong JC, Bestebroer TM, Rimmelzwaan GF, Osterhaus AD, Fouchier RA. 2004. Mapping the antigenic and genetic evolution of influenza virus. Science 305:371-376. http://dx.doi.org/10 $.1126 /$ science. 1097211

11. Bedford T, Suchard MA, Lemey P, Dudas G, Gregory V, Hay AJ, McCauley JW, Russell CA, Smith DJ, Rambaut A. 2014. Integrating influenza antigenic dynamics with molecular evolution. eLife 3:e01914. http://dx.doi.org/10.7554/eLife.01914.

12. Koel BF, Burke DF, Bestebroer TM, van der Vliet S, Zondag GC, Vervaet G, Skepner E, Lewis NS, Spronken MI, Russell CA, Eropkin MY, Hurt AC, Barr IG, de Jong JC, Rimmelzwaan GF, Osterhaus AD, Fouchier RA, Smith DJ. 2013. Substitutions near the receptor binding site determine major antigenic change during influenza virus evolution. Science 342:976-979. http://dx.doi.org/10.1126/science.1244730.

13. Koel BF, Mogling R, Chutinimitkul S, Fraaij PL, Burke DF, van der Vliet S, de Wit E, Bestebroer TM, Rimmelzwaan GF, Osterhaus AD, Smith DJ, Fouchier RA, de Graaf M. 2015. Identification of amino acid substitutions supporting antigenic change of $\mathrm{A}(\mathrm{H} 1 \mathrm{~N} 1) \mathrm{pdm} 09$ viruses. J Virol 89:3763-3775. http://dx.doi.org/10.1128/JVI.02962-14.

14. Sanjuan R, Nebot MR, Chirico N, Mansky LM, Belshaw R. 2010. Viral mutation rates. J Virol 84:9733-9748. http://dx.doi.org/10.1128/JVI .00694-10.

15. Drake JW, Holland JJ. 1999. Mutation rates among RNA viruses. Proc Natl Acad Sci U S A 96:13910-13913. http://dx.doi.org/10.1073/pnas.96 .24 .13910

16. Lauring AS, Frydman J, Andino R. 2013. The role of mutational robustness in RNA virus evolution. Nat Rev Microbiol 11:327-336. http://dx.doi org/10.1038/nrmicro3003.

17. Domingo E, Sheldon J, Perales C. 2012. Viral quasispecies evolution. Microbiol Mol Biol Rev 76:159-216. http://dx.doi.org/10.1128/MMBR .05023-11.

18. Simen BB, Simons JF, Hullsiek KH, Novak RM, Macarthur RD, Baxter JD, Huang C, Lubeski C, Turenchalk GS, Braverman MS, Desany B, Rothberg JM, Egholm M, Kozal MJ, Terry Beirn Community Programs for Clinical Research on, AIDS. 2009. Low-abundance drug-resistant viral variants in chronically HIV-infected, antiretroviral treatment-naive patients significantly impact treatment outcomes. J Infect Dis 199:693701. http://dx.doi.org/10.1086/596736.

19. Ghedin E, Holmes EC, DePasse JV, Pinilla LT, Fitch A, Hamelin ME, Papenburg J, Boivin G. 2012. Presence of oseltamivir-resistant pandemic A/H1N1 minor variants before drug therapy with subsequent selection and transmission. J Infect Dis 206:1504-1511. http://dx.doi.org/10.1093 /infdis/jis571.

20. Wilker PR, Dinis JM, Starrett G, Imai M, Hatta M, Nelson CW, O'Connor DH, Hughes AL, Neumann G, Kawaoka Y, Friedrich TC. 2013. Selection on haemagglutinin imposes a bottleneck during mammalian transmission of reassortant $\mathrm{H} 5 \mathrm{~N} 1$ influenza viruses. Nat Commun 4:2636. http://dx.doi.org/10.1038/ncomms3636.

21. Greenlee RT. 2003. Measuring disease frequency in the Marshfield Epidemiologic Study Area (MESA). Clin Med Res 1:273-280. http://dx.doi .org/10.3121/cmr.1.4.273

22. Ohmit SE, Thompson MG, Petrie JG, Thaker SN, Jackson ML, Belongia EA, Zimmerman RK, Gaglani M, Lamerato L, Spencer SM, Jackson L, Meece JK, Nowalk MP, Song J, Zervos M, Cheng PY, Rinaldo CR, Clipper L, Shay DK, Piedra P, Monto AS. 2014. Influenza vaccine effectiveness in the 2011-2012 season: protection against each circulating virus and the effect of prior vaccination on estimates. Clin Infect Dis 58:319-327. http://dx.doi.org/10.1093/cid/cit736.

23. Centers for Disease Control and Prevention. 2013. Early estimates of seasonal influenza vaccine effectiveness-United States, January 2013. MMWR Morb Mortal Wkly Rep 62:32-35.

24. Skehel JJ, Hay AJ. 1978. Nucleotide sequences at the $5^{\prime}$ termini of influenza virus RNAs and their transcripts. Nucleic Acids Res 5:1207-1219. http://dx.doi.org/10.1093/nar/5.4.1207.

25. Edgar RC. 2004. MUSCLE: a multiple sequence alignment method with reduced time and space complexity. BMC Bioinformatics 5:113. http://dx .doi.org/10.1186/1471-2105-5-113.

26. Guindon S, Dufayard JF, Lefort V, Anisimova M, Hordijk W, Gascuel O. 2010. New algorithms and methods to estimate maximum-likelihood 
phylogenies: assessing the performance of PhyML 3.0. Syst Biol 59:307321. http://dx.doi.org/10.1093/sysbio/syq010.

27. Guindon S, Gascuel O. 2003. A simple, fast, and accurate algorithm to estimate large phylogenies by maximum likelihood. Syst Biol 52:696-704. http://dx.doi.org/10.1080/10635150390235520.

28. Kofler R, Orozco-ter Wengel P, De Maio N, Pandey RV, Nolte V, Futschik A, Kosiol C, Schlotterer C. 2011. PoPoolation: a toolbox for population genetic analysis of next generation sequencing data from pooled individuals. PLoS One 6:e15925. http://dx.doi.org/10.1371 /journal.pone.0015925.

29. Wang ML, Katz JM, Webster RG. 1989. Extensive heterogeneity in the hemagglutinin of egg-grown influenza viruses from different patients. Virology 171:275-279. http://dx.doi.org/10.1016/0042-6822(89)90538-2.

30. Robertson JS, Bootman JS, Newman R, Oxford JS, Daniels RS, Webster RG, Schild GC. 1987. Structural changes in the haemagglutinin which accompany egg adaptation of an influenza $\mathrm{A}(\mathrm{H} 1 \mathrm{~N} 1)$ virus. Virology 160: 31-37. http://dx.doi.org/10.1016/0042-6822(87)90040-7.

31. Schild GC, Oxford JS, de Jong JC, Webster RG. 1983. Evidence for host-cell selection of influenza virus antigenic variants. Nature 303:706709. http://dx.doi.org/10.1038/303706a0.

32. Quail MA, Smith M, Coupland P, Otto TD, Harris SR, Connor TR, Bertoni A, Swerdlow HP, Gu Y. 2012. A tale of three next generation sequencing platforms: comparison of Ion Torrent, Pacific Biosciences, and Illumina MiSeq sequencers. BMC Genomics 13:341. http://dx.doi.org /10.1186/1471-2164-13-341.

33. Loman NJ, Misra RV, Dallman TJ, Constantinidou C, Gharbia SE, Wain J, Pallen MJ. 2012. Performance comparison of benchtop highthroughput sequencing platforms. Nat Biotechnol 30:434-439. http://dx .doi.org/10.1038/nbt.2198.

34. European Centre for Disease Prevention and Control. 2013. Influenza virus characterisation, Summary Europe, July 2013. European Centre for Disease Prevention and Control, Solna, Sweden.

35. European Centre for Disease Prevention and Control. 2014. Influenza virus characterisation, Summary Europe, July 2014. European Centre for Disease Prevention and Control, Solna, Sweden.

36. Jin H, Zhou H, Liu H, Chan W, Adhikary L, Mahmood K, Lee MS, Kemble G. 2005. Two residues in the hemagglutinin of A/Fujian/411/02like influenza viruses are responsible for antigenic drift from A/Panama/ 2007/99. Virology 336:113-119. http://dx.doi.org/10.1016/j.virol.2005.03 .010 .

37. Barr IG, Russell C, Besselaar TG, Cox NJ, Daniels RS, Donis R, Engelhardt OG, Grohmann G, Itamura S, Kelso A, McCauley J, Odagiri T, Schultz-Cherry S, Shu Y, Smith D, Tashiro M, Wang D, Webby R, $\mathrm{Xu} \mathrm{X,} \mathrm{Ye} \mathrm{Z,} \mathrm{Zhang} \mathrm{W.} \mathrm{2014.} \mathrm{WHO} \mathrm{recommendations} \mathrm{for} \mathrm{the} \mathrm{viruses} \mathrm{used}$ in the 2013-2014 northern hemisphere influenza vaccine: epidemiology, antigenic, and genetic characteristics of influenza A(H1N1)pdm09, $\mathrm{A}(\mathrm{H} 3 \mathrm{~N} 2)$ and B influenza viruses collected from October 2012 to January 2013. Vaccine 32:4713-4725. http://dx.doi.org/10.1016/j.vaccine.2014.02 .014 .

38. Nakajima S, Nakajima K, Nobusawa E, Zhao J, Tanaka S, Fukuzawa K. 2007. Comparison of epitope structures of H3HAs through protein modeling of influenza A virus hemagglutinin: mechanism for selection of antigenic variants in the presence of a monoclonal antibody. Microbiol Immunol 51:1179-1187. http://dx.doi.org/10.1111/j.1348-0421 .2007.tb04013.x.

39. Neher RA, Bedford T. 2015. nextflu: real-time tracking of seasonal influenza virus evolution in humans. Bioinformatics 31:3546-3548. http://dx .doi.org/10.1093/bioinformatics/btv381.

40. Squires RB, Noronha J, Hunt V, García-Sastre A, Macken C, Baumgarth N, Suarez D, Pickett BE, Zhang Y, Larsen CN, Ramsey A, Zhou L, Zaremba S, Kumar S, Deitrich J, Klem E, Scheuermann RH. 2012. Influenza research database: an integrated bioinformatics resource for influenza research and surveillance. Influenza Other Respir Viruses 6:404416. http://dx.doi.org/10.1111/j.1750-2659.2011.00331.x.
41. Li Y, Myers JL, Bostick DL, Sullivan CB, Madara J, Linderman SL, Liu Q, Carter DM, Wrammert J, Esposito S, Principi N, Plotkin JB, Ross TM, Ahmed R, Wilson PC, Hensley SE. 2013. Immune history shapes specificity of pandemic H1N1 influenza antibody responses. J Exp Med 210:1493-1500. http://dx.doi.org/10.1084/jem.20130212.

42. Guarnaccia T, Carolan LA, Maurer-Stroh S, Lee RT, Job E, Reading PC, Petrie S, McCaw JM, McVernon J, Hurt AC, Kelso A, Mosse J, Barr IG, Laurie KL. 2013. Antigenic drift of the pandemic 2009 A(H1N1) influenza virus in A ferret model. PLoS Pathog 9:e1003354. http://dx.doi.org/10 .1371/journal.ppat.1003354.

43. Miller MS, Gardner TJ, Krammer F, Aguado LC, Tortorella D, Basler CF, Palese P. 2013. Neutralizing antibodies against previously encountered influenza virus strains increase over time: a longitudinal analysis. Sci Transl Med 5:198ra107. http://dx.doi.org/10.1126/scitranslmed.3006637.

44. Fazekas DSG, Webster RG. 1966. Disquisitions of original antigenic sin. I. Evidence in man. J Exp Med 124:331-345.

45. Fonville JM, Wilks SH, James SL, Fox A, Ventresca M, Aban M, Xue L, Jones TC, Le NM, Pham QT, Tran ND, Wong Y, Mosterin A, Katzelnick LC, Labonte D, Le TT, van der Net G, Skepner E, Russell CA, Kaplan TD, Rimmelzwaan GF, Masurel N, de Jong JC, Palache A, Beyer WE, Le QM, Nguyen TH, Wertheim HF, Hurt AC, Osterhaus AD, Barr IG, Fouchier RA, Horby PW, Smith DJ. 2014. Antibody landscapes after influenza virus infection or vaccination. Science 346:996-1000. http://dx .doi.org/10.1126/science.1256427.

46. Murcia PR, Baillie GJ, Stack JC, Jervis C, Elton D, Mumford JA, Daly J, Kellam P, Grenfell BT, Holmes EC, Wood JL. 2013. Evolution of equine influenza virus in vaccinated horses. J Virol 87:4768-4771. http: //dx.doi.org/10.1128/JVI.03379-12.

47. Das SR, Hensley SE, Ince WL, Brooke CB, Subba A, Delboy MG, Russ G, Gibbs JS, Bennink JR, Yewdell JW. 2013. Defining influenza A virus hemagglutinin antigenic drift by sequential monoclonal antibody selection. Cell Host Microbe 13:314-323. http://dx.doi.org/10.1016/j.chom .2013.02.008.

48. Illingworth CJ, Fischer A, Mustonen V. 2014. Identifying selection in the within-host evolution of influenza using viral sequence data. PLoS Comput Biol 10:e1003755. http://dx.doi.org/10.1371/journal.pcbi.1003755.

49. Skowronski DM, Janjua NZ, De Serres G, Sabaiduc S, Eshaghi A, Dickinson JA, Fonseca K, Winter AL, Gubbay JB, Krajden M, Petric M, Charest H, Bastien N, Kwindt TL, Mahmud SM, Van Caeseele P, Li Y. 2014. Low 2012-13 influenza vaccine effectiveness associated with mutation in the egg-adapted $\mathrm{H} 3 \mathrm{~N} 2$ vaccine strain not antigenic drift in circulating viruses. PLoS One 9:e92153. http://dx.doi.org/10.1371/journal .pone.0092153.

50. World Health Organization. 2014. Recommended composition of influenza virus vaccines for use in the 2014-2015 northern hemisphere influenza season. Wkly Epidemiol Rec 89:93-104.

51. O'Donnell CD, Vogel L, Wright A, Das SR, Wrammert J, Li GM, McCausland M, Zheng NY, Yewdell JW, Ahmed R, Wilson PC, Subbarao K. 2012. Antibody pressure by a human monoclonal antibody targeting the 2009 pandemic H1N1 virus hemagglutinin drives the emergence of a virus with increased virulence in mice. mBio 3:e00120-12. http: //dx.doi.org/10.1128/mBio.00120-12.

52. Russell CA, Jones TC, Barr IG, Cox NJ, Garten RJ, Gregory V, Gust ID, Hampson AW, Hay AJ, Hurt AC, de Jong JC, Kelso A, Klimov AI, Kageyama T, Komadina N, Lapedes AS, Lin YP, Mosterin A, Obuchi M, Odagiri T, Osterhaus AD, Rimmelzwaan GF, Shaw MW, Skepner E, Stohr K, Tashiro M, Fouchier RA, Smith DJ. 2008. The global circulation of seasonal influenza A (H3N2) viruses. Science 320:340-346. http: //dx.doi.org/10.1126/science.1154137.

53. Weis WI, Brunger AT, Skehel JJ, Wiley DC. 1990. Refinement of the influenza virus hemagglutinin by simulated annealing. J Mol Biol 212: 737-761. http://dx.doi.org/10.1016/0022-2836(90)90234-D. 